\title{
Pattern of Household Activities and its Effects on Low Back Pain Among Bangladeshi Housewives
}

\author{
Arju $\mathrm{A}^{1^{*}}$, Saha $\mathrm{S}^{1}$, Lama $\mathrm{N}^{2}$, Ahmed $\mathrm{K}^{3}$, Rahman $\mathrm{MH}^{4}$, Kabir $\mathrm{MA}^{5}$ \\ Centre for the Rehabilitation of the Paralysed, Savar, Dhaka, Bangladesh; ${ }^{2}$ Upendra Devkota \\ Memorial National Institute of Neurological and Allied Sciences, Nepal; ${ }^{3}$ Institute of Health \\ Technology, Dhaka, Bangladesh; ${ }^{4}$ School of Science and Technology, Bangladesh Open University, \\ Gazipur, Bangladesh; ${ }^{5}$ Department of Statistics, Jahangirnagar University, Savar, Dhaka, \\ Bangladesh
}

\begin{abstract}
Background: Housework is traditionally an unpaid labour performed by women. It involves routine and compulsory household maintenance tasks can create musculoskeletal disorder like Law back pain (LBP).

Objective: The main objective of the study was to identify the effects of household activities on LBP among Bangladeshi housewives.

Methods: A descriptive cross-sectional study was carried out among 255 respondents. At the Musculoskeletal department of Centre for the Rehabilitation of the Paralysed (CRP), Savar, Dhaka. The questionnaire was designed according to Bangladesh perspectives regarding household activities that housewife do at home. Severity of pain was assessed using Visual Analogue Scale (VAS) and data ware collected using face to face interview.

Results: Study found that household activities like cooking and chopping $(p<.0001)$, washing dish and cloth $(p<.0001)$, sweeping floor/cleaning toilet $(p<.0001)$ were significantly associated with LBP. The results from regression analysis showed that having LBP compare with the time duration of cooking $(\mathrm{OR}=11.2$; $\mathrm{CI}=2.62-47.73)$, chopping $(\mathrm{OR}=2.67$; $\mathrm{CI}=1.44-4.93)$, washing dish $(\mathrm{OR}=3.33 ; \mathrm{CI}=1.50-7.39)$, washing cloth $(\mathrm{OR}=5.71 ; \mathrm{CI}=2.94-11.10)$, sweeping floor $(\mathrm{OR}=4.71 ; \mathrm{CI}=2.33-9.53)$ was significantly higher among housewife than who don't do this activity at home.

Conclusion: This study revealed that all of married women had to do their household activities for a long period in awkward posture. Elderly housewives suffer more, as the duration of married life and duration of doing household activities are high among them. Among the activities coking, chopping, washing dish, washing cloth, lift heavy objects and sweeping the floor/cleaning toilet were done by maximum housewives.
\end{abstract}

Keywords: Low back pain, Visual analogue scale, Bangladeshi housewives, Quality of life

\section{Introduction}

Low back pain is a common musculoskeletal symp tom that may be either acute or chronic. It may be caused by a condition of diseases and disorders that affect the lumbar spine. It can be defined as pain localised below the line of the twelfth rib and above the inferior gluteal folds, with or without leg pain and it can be classified as "specific" or "non-specific". ${ }^{1}$ Chronic low back pain (CLBP) is a serious medical and social problem which is one of the most common causes of disability. ${ }^{2}$

The prevalence of LBP is $58.6 \%$ among housewives in Bangladesh. ${ }^{3}$ Study titled 'Women's contribution to national economy' revealed that in Bangladesh

*Correspondence: Asma Arju, Centre for the Rehabilitation of the Paralysed, Savar,Dhaka,Bangladesh,e-mail: asma.arju@gmail.com, ORCID: 0000-0002-2067-469x
$81 \%$ percent women are directly involved in household activities. The study also revealed that a housewife spends 16 to 20 hours a day for household works on an average by engaging herself in 45 types of works. The finding of the research should they have no holiday and even no leisure time. The village women have to do more works than the women living in urban areas. As the rural women are involved in agricultural activities, cattle and poultry farming, handicrafts, cooking, water fetching, cleaning the house, take care of family members and many more. ${ }^{4}$ Another study done among slum women at Dhaka city, where they found $65 \%$ housewives had LBP. Regular household work and posture like bending activities is responsible for developing low back pain among women living in slum area. ${ }^{5}$ A study in Qatar reported that LBP can have a substantial negative impact on the quality of life. They 
found risk factors of LBP are multi-factorial and include physical factors, social demographic characteristics, habits and psychological factors. ${ }^{2}$

Housework is traditionally an unpaid labour performed by women. It involves routine and compulsory household maintenance tasks like cleaning, cooking, washing, lifting, purchasing, etc and family care duties like child rearing and other care-giving responsibilities that require substantial physical, emotional and intellectual labour. ${ }^{6}$ Studies have found that housework can be more energy intensive than some types of paid work. ${ }^{7}$ It is a source of hazards comparable to other occupational settings. Research has also found associations between housework and upper-extremity and lower back disorders. ${ }^{8}$

Women's working conditions also include other less visible stressors like highly repetitive work and prolonged sitting or standing work even thousands of times in a day where muscles are contracted for long periods. These movements can individually make significant demands on the human body. It can create musculoskeletal and circulatory problems due to interference with circulation. ${ }^{9}$ A chair the wrong height or a counter the wrong width may cause constant overuse of the same tendons or joints yet the observer may see no problem. This explains why sewing machine operation is associated with a very high probability of disability though it classed as light work. ${ }^{10}$ Cleaning activities like dusting high surfaces, bending over toilets often require prolong static posture for long periods of time which results in back and other musculoskeletal problems. ${ }^{11}$

The housewives form the core that nurtures the society. Available study according to Bangladesh perspectives is very less to find out how much or what factors are affecting female or housewives LBP patients. Thus the purpose of the study was to evaluate the effects of household activities on LBP in housewives to determine the effect of social environment on LBP. However, this study would enhance the evidence based practice in physiotherapy profession and the rehabilitation field as well. Moreover, the preventive aspects of treatment session would ensure throughout the proper rehabilitation for patients with LBP which would be helpful to lead a good quality of life.

\section{Materials and Methods}

In this study, quantitative cross sectional research design with convenience sampling method were used among the patients, who were continuing physiotherapy treatments in the musculoskeletal unit of physiotherapy department at CRP from January to April, 2018. Study samples were 255 housewives with mechanical LBP with or without radiculopathy. Sample size was calculated according to the cross sectional design formula as given below:

$$
\begin{aligned}
\mathrm{n} & =\left\{\frac{Z\left(1-\frac{\alpha}{2}\right)}{d}\right\}^{2} \times p q \\
& =\left(\frac{1.96}{0.05}\right)^{2} \times 0.586 \times 0.414 \\
& =1536.64 \times 0.242604 \approx 372
\end{aligned}
$$

Here, $Z\left(1-\frac{\alpha}{2}\right)=1.96$

$\mathrm{d}=0.05$

$$
\mathrm{P}=0.586
$$

$\mathrm{q}=1-\mathrm{p}$

$$
\begin{aligned}
& =1-0.586 \\
& =0.414
\end{aligned}
$$

Female subjects, the housewives aged 20-65 years who have mechanical LBP and were interested to participate were included in the study.

The subjects who had severe neurological problem, osteoporosis, previously history of CVD or heart disease, currently pregnant, doing job or service, severe general illness were excluded written.

Following methods were used for data collection including:

- structured questionnaire was used for descriptive information;

- modified IPAQ questionnaire for physical activity measurement,

- VAS Scale for pain measurement; and

- collected data through face to face interview

The data were analysed using the Statistical Package for Social Sciences (SPSS) version 16.0 and was reflected as descriptive statistics. Chisquare $\left(\chi^{2}\right)$ tests and Pearson correlation tests were performed assess the association between descriptive variables (socio-demographic and household activity related) with the LBP. Then binary logistic regression was used to find out the probability of having the dependent variable (LBP) with the independent variable (household activities).

Researcher ensured the quality assurance in research (QAR) comprising all the techniques, systems and resources that are deployed to give 
assurance about the care and control with which research had been conducted. The researcher took the responsibilities to plan a transparent research project. Data collector received training to ensure the competence of data collection.

The study proposal was reviewed by the ethical board/committee of CRP and it was approved by Bangladesh Health Professions Institute (BHPI), the academic institute of Dhaka University. Permission was obtained for the patient records for participant contact address. A written information sheet was shared to participants informing them about the aims and significance of the study and if the participants agree to participate in the study then her consent was taken.

\section{Results}

The common age group of the housewife was 30-50 years that was $60 \%$ and the second highest was laid in between 20-30 years which was $23.1 \%$. Among them $53.7 \%$ doing their household activities for 10 30 years and $30.2 \%$ housewives were doing their household activities for more than 30 years.

Table I: Association between household activities and LBP $(\mathrm{n}=255)$

\begin{tabular}{|c|c|c|c|c|c|}
\hline Characteristics & Response & Frequency & $(\%)$ & $\chi^{2}$ value & r-value \\
\hline \multirow[t]{2}{*}{ Cooking } & Yes & 238 & 93.3 & $66.23 * * *$ & .407 \\
\hline & No & 17 & 6.7 & & \\
\hline \multirow[t]{2}{*}{ Chopping } & Yes & 230 & 90.2 & $102.7 * * *$ & .483 \\
\hline & No & 25 & 9.8 & & \\
\hline \multirow[t]{2}{*}{ Washing dish } & Yes & 198 & 77.6 & $89.36^{* * *}$ & .525 \\
\hline & No & 57 & 22.4 & & \\
\hline \multirow[t]{2}{*}{ Washing cloth } & Yes & 195 & 76.5 & $152.48^{* * *}$ & .654 \\
\hline & No & 60 & 23.5 & & \\
\hline \multirow[t]{2}{*}{ Sweep floor/cleaning toilet } & Yes & 185 & 72.5 & $133.45^{* * *}$ & .643 \\
\hline & No & 70 & 27.5 & & \\
\hline \multirow[t]{2}{*}{ Lift heavy objects } & Yes & 104 & 40.8 & $191.73 * * *$ & .801 \\
\hline & No & 151 & 59.2 & & \\
\hline \multirow[t]{2}{*}{ Carry heavy objects } & Yes & 92 & 36.1 & $210.31 * * *$ & .836 \\
\hline & No & 163 & 63.9 & & \\
\hline \multirow[t]{2}{*}{ Look after cattle } & Yes & 57 & 22.4 & $136.27^{* * *}$ & .683 \\
\hline & No & 198 & 77.6 & & \\
\hline \multirow[t]{2}{*}{ Caring for family members } & Yes & 74 & 29 & $16.04 * * *$ & .630 \\
\hline & No & 181 & 71 & & \\
\hline \multirow[t]{2}{*}{ Travel for groceries } & Yes & 67 & 26.3 & $153.32 * * *$ & .724 \\
\hline & No & 188 & 73.7 & & \\
\hline \multirow[t]{2}{*}{ Pass leisure time } & Yes & 249 & 97.6 & $6.097^{*}$ & .138 \\
\hline & No & 6 & 2.4 & & \\
\hline \multicolumn{6}{|c|}{ Percentage Distribution of Activities during Leisure Time } \\
\hline \multirow[t]{8}{*}{ Activities during Leisure time } & Pray & & 16.9 & & \\
\hline & Sew & & 16.5 & & \\
\hline & Gardening & & 4.7 & & \\
\hline & Read books & & 9.8 & & \\
\hline & Watch TV & & & & \\
\hline & Gossiping & & 33.3 & & \\
\hline & Others & & 23.1 & & \\
\hline & & & 14.1 & & \\
\hline
\end{tabular}

$p$ value $\left(p<0.05^{*}, p<0.01^{* *}, p<0.001^{* * *}\right)$; Pearson correlation (r value)

Among 225 participants $93.3 \%$ did cook and $90.2 \%$ did chop; $77.6 \%$ and $76.5 \%$ wash their dish and cloth which was significantly associated at the significant level of $(p<.0001)$ and positively correlated with LBP (table I). The percentage of the sweep the floor and cleaning toilet, lift heavy objects, carry heavy objects, look after cattle, caring for family members, travel for groceries and pass leisure time was significantly associated and positively correlated with LBP at the significance level of $p$ value $(p<0.001)$.

Maximum participants did their cooking in standing and low sitting position which was $41.2 \%$ and $38.0 \%$ respectively (table II). 
Table II: Association between position of doing household activities and LBP $(\mathrm{n}=255)$

\begin{tabular}{|c|c|c|c|c|c|c|c|}
\hline \multirow[t]{2}{*}{ Characteristics } & \multicolumn{7}{|c|}{ Position of the activities } \\
\hline & $\begin{array}{l}\text { Low } \\
\text { sitting }\end{array}$ & Bending & Standing & $\begin{array}{l}\text { Sitting in a } \\
\text { chair }\end{array}$ & Others & $\bigotimes^{2}$ value & r-value \\
\hline Cooking & 38.0 & 3.1 & 41.2 & 2.0 & 7.8 & $89.36^{* * *}$ & 0.153 \\
\hline Chopping & 62.4 & 10.6 & 3.9 & 4.3 & 9.4 & $13.25^{*}$ & 0.045 \\
\hline Washing dish & 34.1 & 10.6 & 20.8 & 5.9 & 6.3 & $103.95 * * *$ & 0.197 \\
\hline Washing cloth & 38.4 & 30.6 & 2.0 & .4 & 5.9 & $24.73 * * *$ & 0.196 \\
\hline $\begin{array}{l}\text { Sweeping/cleaning } \\
\text { toilet }\end{array}$ & 14.1 & 47.5 & 11.0 & - & - & $145.28 * * *$ & 0.518 \\
\hline Look after cattle & 10.2 & 3.5 & 6.7 & 1.6 & .4 & $146.66^{* * *}$ & 0.638 \\
\hline $\begin{array}{l}\text { Caring for family } \\
\text { members }\end{array}$ & 5.9 & 5.5 & 11.8 & 2.0 & 3.9 & $154.27 * * *$ & 0.509 \\
\hline Leisure time & 8.6 & 5.1 & 10.6 & 22.7 & 50.6 & $28.79 * * *$ & -.106 \\
\hline
\end{tabular}

However, $62.4 \%$ participants did their chopping in low sitting position where $10.6 \%$ participants did in bending position. Among them, 34.1\% wash their dish in low sitting position and $20.8 \%$ wash in standing position.

Table III: Percentage distribution of the pain level of doing household activities $(n=255)$

\begin{tabular}{lccc}
\hline Characteristics & \multicolumn{3}{c}{ Pain level of doing Household } \\
activities \% \\
\cline { 2 - 4 } & $\begin{array}{l}\text { Mild } \\
\text { pain }\end{array}$ & $\begin{array}{c}\text { Moderate } \\
\text { pain (4-6) }\end{array}$ & $\begin{array}{c}\text { Severe pain } \\
\text { (7-10) }\end{array}$ \\
& $\mathbf{( 0 - 3 )}$ & & \\
Cooking & 21.6 & 47.5 & 31 \\
Chopping & 19.6 & 53.7 & 26.7 \\
Washing dish & 45.1 & 39.2 & 15.7 \\
$\begin{array}{l}\text { Washing cloth } \\
\text { Sweeping/cleaning }\end{array}$ & 31.8 & 41.2 & 27.1 \\
toilet & 42.0 & 29.4 & 28.6 \\
$\begin{array}{l}\text { Lift heavy objects } \\
\text { Carry heavy }\end{array}$ & 65.9 & 17.6 & 16.5 \\
objects & 68.2 & 19.2 & 12.5 \\
$\begin{array}{l}\text { Look after cattle } \\
\text { Caring for family }\end{array}$ & 86.7 & 9.0 & 4.3 \\
members & & 10.6 & 5.1 \\
$\begin{array}{l}\text { Travel } \\
\text { groceries }\end{array}$ & 82.4 & 12.9 & 4.7 \\
$\begin{array}{l}\text { Pass leisure time } \\
\text { for }\end{array}$ & 50.2 & 35.3 & 14.5 \\
\hline
\end{tabular}

Maximum participants $38.4 \%$ wash their cloth in low sitting position following in bending position $30.6 \%$. In case of sweeping the floor and cleaning the toilet maximum participants $47.5 \%$ did in bending position following in low sitting position
(14.1\%). In all of participants $50.6 \%$ passed their leisure time in various positions like lying in a bed or gossiping in bed or watching TV in lying position. The position of doing activities were also highly significantly associated and positively correlated with LBP at the significance level of $p$ value $(p<0.001)$ except chopping at $p$ value $(p<0.05)$ level.

Maximum participants felt mild to moderate pain during their various household activities showed in the (table III). Among them during cooking (47.5\%) and chopping (53.7\%) maximum participants felt moderate LBP where during wash dish $(45.1 \%)$ and cloth $(41.2 \%)$ maximum participants felt mild to moderate pain.

Table IV: Percentage distribution of the psychological condition of the housewife

\begin{tabular}{lccc}
\hline Characteristics & Response & Frequency & \% \\
\hline Feel monotonous & Yes & 174 & 68.2 \\
& No & 81 & 31.8 \\
Feel exhausted due to & Yes & 180 & 70.6 \\
household activities & No & 75 & 29.4 \\
\hline
\end{tabular}

As the participants doing their household activities for a long period of time therefore (table IV) showed maximum (68.2\%) participants felt monotonous and $70.6 \%$ felt exhausted at the end of the day.

The results from the binary logistic regressions analysis in (table V) showed that the probability of having pain was $9.05 \quad(\mathrm{CI}=3.50-23.4)$ times significantly higher in between age range 30-40 years, $2.15(\mathrm{CI}=1.01-4.57)$ times higher in between age range $40-50$ years and 1.38 times higher over 50 years compared with age range $20-30$ years. 
Table V: Odds ratio and $95 \%$ CI of the predictors by LBP

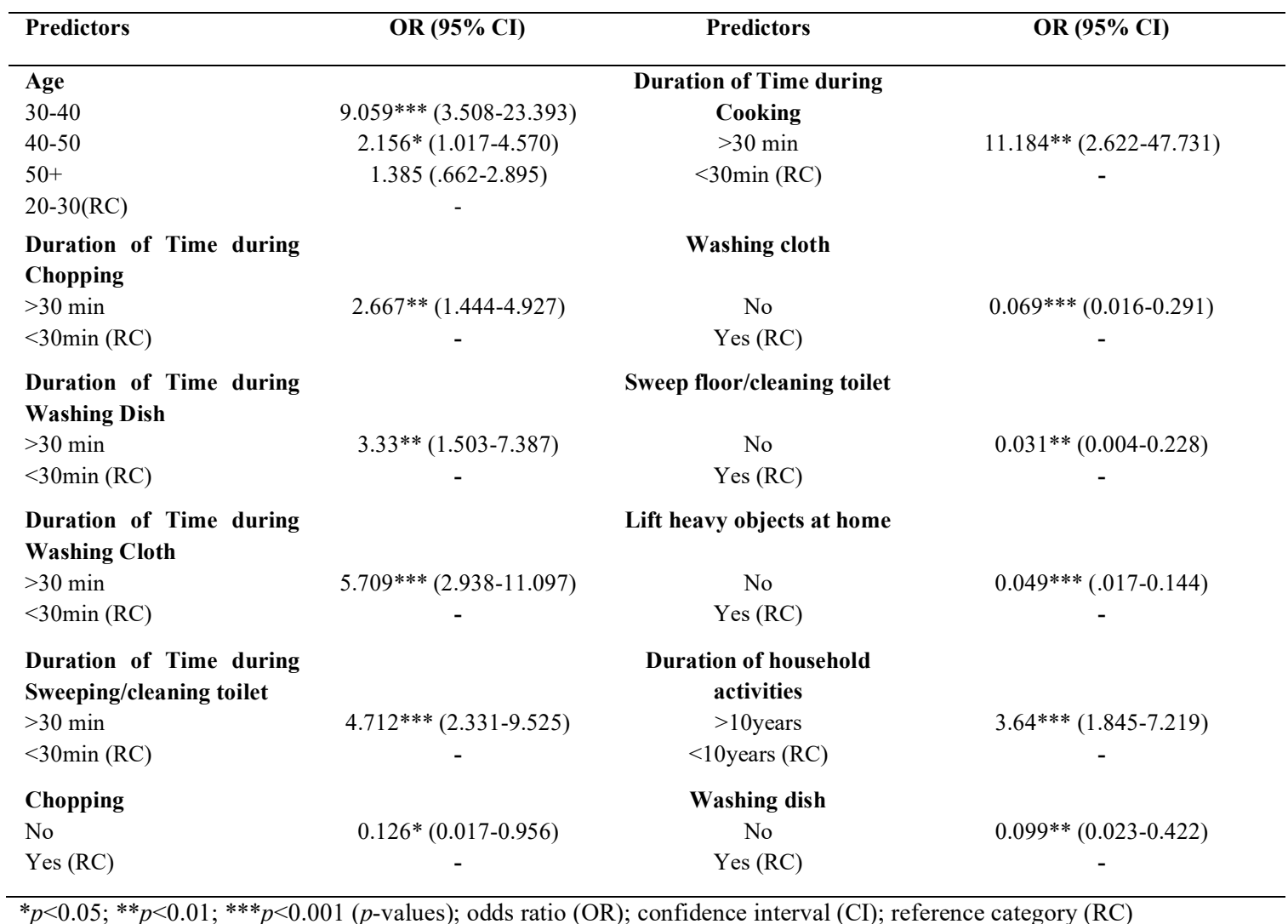

The likelihood of having LBP during chopping 0.126 ( $\mathrm{CI}=0.02-0.95)$, washing cloth 0.069 ( $\mathrm{CI}=0.01-0.29)$ and lift heavy objects $0.049(\mathrm{CI}=.017-0.15)$ was significantly less for who didn't chop than who didn't did this activities at home than who did.

The probability of having LBP was 11.18 (CI=2.6247.73) times significantly higher for who cook more than 30 minutes compared to those who cook for less than 30 minute at home among the housewives. In consequence, the probability of having LBP was 2.7(CI=1.45-4.92), 3.33(CI=1.50-7.38), 5.709(CI=2.93$11.09), 4.712(\mathrm{CI}=2.33-9.52)$ times significantly higher for who chopping, washing dishes, washing cloth and sweeping floor/clean toilet respectively more than 30 minutes compared to those who did for less than 30 minute at home among the housewives. Among the participants who did their household activities for more than 10 years, the likelihood of feeling monotonous was 3.64(CI=1.84-7.21) times significantly higher compared with who did for less than 10 years.

\section{Discussion}

The findings of the present study showed that the prevalence of recent episodes of LBP was $45 \%$ and
$55.0 \%$ respondents had CLBP. The prevalence rate of LBP in Bangladesh was much higher than the rate observed in developed countries like Australia 25.6\%, Canada 28.7\%, the United Kingdom 36.1\% and Sweden $39.2 \%$, with a very close to the rate in Qatar $56.5 \%$, Africa $62 \%$, China $64 \%$ and India $83 \%$. ${ }^{2,12}$

Present study found that maximum participants did various type of work at home on which participation rate was remarkably higher in cooking, chopping, washing dishes, washing cloth and sweeping floor/cleaning toilet. These findings were very equivalent with one study in Bangladesh on which they also found that the housewives participation rate was higher in cleaning house (92\%), washing cloth $(81 \%)$, child care $(80 \%)$, cooking and preparation of meal $(81 \%)$ and look after cattle $(52 \%){ }^{13}$ These activities required various awkward postures like prolonged sitting/standing including bending, kneeling, squatting and repetitive movements. Study found, maximum participants did their cooking in standing posture (41.2\%) following in low sitting position. Beside this, maximum participant did their housework in low sitting and bending position like chopping (73\%), washing dish (45\%), washing cloth (69\%), sweeping floor/cleaning toilet (61.6\%). These findings were very corresponding with another study 
in Iran where they also found the similar thing among Iranian housewife. ${ }^{14}$ Participants describe that their surrounding environment on which they did their work or the way to complete their daily activities, compel them to develop LBP. Excessive posture stretches posterior longitudinal ligament, approaching of pedicles which causes compression on the nerve roots as well as desensitises mechanoreceptors with consequent loss of the reflex, contraction of stabilizing muscles and increased load over the spine which ultimately create LBP. ${ }^{15}$ Therefore environment is a vital part of daily life or daily activities. If there is any trouble in surrounding environment then this can prevent to fulfil our roles which are appropriate according to ability. ${ }^{16}$ The findings for the activities that participants did at home were highly significant and positively moderate to strongly correlate with LBP. Furthermore, binary logistic regression found that the probability of having LBP was less among who didn't do this activity at home. This finding is in line with literature discussing work exposures related to LBP where they found LBP 1.65 times more frequent who were mostly exposed to trunk flexion and rotation. ${ }^{17}$ Fazli and colleagues conducted one study the Iran and found that heavy weight lifting (1.07, CI 95\%:1.04-2.19) and performing household tasks in awkward postures (bending, kneeling or squatting) associated with back pain (2.17; CI = 1.17-4.01). Posture like bending, kneeling and squatting were associated with LBP. ${ }^{18}$ Habib and his colleagues also found that household tasks such as tidying, mopping, sweeping, washing the floor and cleaning the bathroom may sometimes require awkward working postures, which had potential risk factors for back pain. However, another study with almost similar objectives was conducted in Qatar by Bener and colleagues found that LBP among housewife were significantly associated with prolonged standing $(49.5 \% p=0.026)$, prolonged sitting $(45.4 \% p=0.020)$ and lifting heavy weights $(41.8 \% \quad p<0.039)$. According to binary logistic regression they also found that the probability of having pain was significantly higher if women did their work in prolonged standing $(1.70 ; 95 \% \quad \mathrm{CI}, \quad 1.34-$ $2.16 ; p<0.001)$, prolonged sitting $(2.13 ; 95 \% \mathrm{CI}$, $1.62-2.80 ; p<0.001)$ and lift heavy weight in bending (2.36; 95\% CI, 1.76-3.17; $p<0.001)$.

Investigator of the present study found that housewives felt monotonous due to prolong and repetitive activity at home. According to the findings $68.2 \%$ felt monotonous and $70.6 \%$ felt exhausted at the end of the day. Housewives who did their work for more than ten years, the likelihood of having pain was $3.64(95 \% \mathrm{CI}=1.845-7.219)$ times significantly higher compared with who did less than ten years.
One study in Sri Lanka (2016) supported this result, where they found psychological distress were 1.8 (95\% CI $=1.3-2.6)$ times higher among housewives due to household activities at home. ${ }^{19}$ In contrast, Fazli and his colleagues found in an Iranian study that housewives also felt exhausted due to hard work at home and this factor may affect the women's body posture during work at home.

\section{Conclusion}

This study revealed that all of married women have to do their household activities for a long period in awkward posture. Elderly housewife suffer more as the duration of married life and duration of doing household activities are high among them.

Competing Interests: The authors declare that they have no competing interests.

Funding: None

Ethical approval: Ethical Committee of CRP, Dhaka

Submitted: $24^{\text {th }}$ March, 2019

Final revision received: $12^{\text {th }}$ March, 2020

Accepted: $19^{\text {th }}$ March, 2020

Published: $1^{\text {st }}$ December, 2020

\section{References}

1. Anderson JA. Epidemiological aspects of back pain. Occupational Medicine. 1986; 1;36:90-4. DOI: $10.1093 /$ occmed/36.3.90

2. Bener A, Dafeeah EE, Alnaqbi K. Prevalence and correlates of low back pain in primary care: what are the contributing factors in a rapidly developing country. Asian Spine J. 2014;8:227. DOI: 10.4184/asj.2014.8.3.227

3. Akter S. Prevalence of low back pain among the housewives (Doctoral dissertation, Department of Physiotherapy, Bangladesh Health Professions Institute, CRP).

URL:www.202.4.109.124:8080/handle/123456789/1187

4. Calculate economic values of household activities by women (2008, July 15), The Daily Star. URL:www.thedailystar.net/news-detail-45827

5. Barua SK, Sultana N. Prevalence of Low Back Pain Among Women Living in Slum Areas of Dhaka City. ChattagramMaa-O-Shishu Hospital Med Coll J. 2015; 5;14:47-51.

DOI: $10.3329 /$ cmoshmcj.v14i1.22883

6. Shelton BA, John D. The division of household labor. Annu. Rev. Sociol. 1996; 22:299-322.

DOI: 10.1146/annurev.soc.22.1.299

7. Sujatha T, Shatrugna V, Vidyasagar P, Begum N, Padmavathy KS, Reddy GC, Rao GN. Timed activity studies for assessing the energy expenditure of women from an urban slum in South India. Food Nutr Bull 2003; 24:193-9.

DOI: $10.1177 / 156482650302400205$ 
8. Habib RR, El Zein K, Hojeij S. Hard work at home: musculoskeletal pain among female homemakers. Ergonomics. 2012; 1;55:201-11.

DOI: $10.1080 / 00140139.2011 .574157$

9. Tissot F, Messing K, Stock S. Standing, sitting and associated working conditions in the Quebec population in 1998. Ergonomics. 2005; 22;48:249-69. DOI: $10.1080 / 00140130512331326799$

10. Vezina N, Tierney D, Messing $\mathrm{K}$. When is light work heavy? Components of the physical workload of sewing machine operators working at piecework rates. Appl. Ergon. 1992; 1; 23:268-76.

DOI: 10.1016/0003-6870(92)90155-O

11. Messing K. Women's occupational health: A critical review and discussion of current issues. Women \& Health. 1997; 25; 25:39-68.

DOI: 10.1300/J013v25n04_03

12. Gupta G, Nandini N. Prevalence of low back pain in non working rural housewives of Kanpur, India. Int J Occup Med Environ Health. 2015; 1;28:313-20.

DOI: 10.13075/ijomeh.1896.00299

13. Asaduzzaman M, Kabir RA, Radović-Marković M. Gender inequality in Bangladesh. JWEE. 2015(3-4):54-64.

14. Fazli B, Ansari H, Noorani M, Jafari SM,
Sharifpoor Z, Ansari S. The prevalence of musculoskeletal disorders and its predictors among Iranians' Housewives. Int. J. Epidemiol. 2016; 3:53-62.

URL:www.ijer.skums.ac.ir/article_14900_3023.html

15. Pope MH, Goh KL, Magnusson ML. Spine ergonomics. Ann rev biomed eng. 2002 ;4:49-68. DOI: 10.1146/annurev.bioeng.4.092101.122107

16. World Health Organization. International classification of functioning, disability and health: ICF. World Health Organization; 2001.

17. Pataro SM, Fernandes RD. Heavy physical work and low back pain: the reality in urban cleaning. Rev. Bras. epidemiol. 2014; 17:17-30.

DOI: 10.1590/1809-4503201400010003ENG

18. Reid CR, Bush PM, Karwowski W, Durrani SK. Occupational postural activity and lower extremity discomfort: A review. Int. J. Ind. Ergon. 2010; $1 ;$ 40:247-56.

DOI: 10.1016/j.ergon.2010.01.003

19. Ranasinghe PD, Atukorala I, Samaranayake A, Gunawardana NS. SAT0504 Prevalence and Correlates of Household Work Related Musculoskeletal Disorders in Low Back Region among Sri Lankan Housewives. Ann. Rheum. Dis. 2016; 75:852.2-852

DOI: 10.1136/annrheumdis-2016-eular.2832 